\title{
SISTEM PENDUKUNG KEPUTUSAN PEMILIHAN MOTOR DENGAN METODE SIMPLE ADDITIVE WEIGHTING (SAW)
}

\author{
Hermanto, Nailul Izzah \\ Sekolah Tinggi Teknik Qomaruddin Gresik \\ Hermansanjaya25@gmail.com
}

\begin{abstract}
Abstrak
Sepeda motor merupakan alat transportasi yang sangat efektif dan efisien. Peningkatan jumlah produk motor saat ini membuat konsumen memiliki pilihan tersendiri untuk membeli sepeda motor yang tepat dan sesuai dengan keinginan, kebutuhan dan kemampuannya. Tujuan penelitian ini adalah membuat desain sistem pendukung keputusan pemilihan produk motor dengan metode Simple Additive Weighting (SAW). Sistem pendukung keputusan ini hanya membandingkan 3 produk motor Honda,Yamaha dan Suzuki. Obyek penelitian di lakukan di wilayah Kabupaten Gresik.Hasil dari penelitian ini adalah sistem pendukung keputusan pemilihan produk motor dengan metode Simple Additive Weighting (SAW) yang mempermudah pengguna dalam menjalankan sistem pendukung keputusan pemilihan produk motor terbaik dan mendukung keputusan pembeli motor dalam memilih motor sesuai dengan kriteria yang di inginkan.
\end{abstract}

Kata Kunci: Sistem pendukung keputusan, simple additive weighting, pemilihan motor

\begin{abstract}
Motorcycle is a very effective and efficient means of transportation. The increasing number of motorcycle products now makes consumers have their own choice to buy the right motorcycle and according to their desires, needs and abilities. The purpose of this study is to create a system design for decision support for motor product selection using the Simple Additive Weighting (SAW) method. This decision support system only compares 3 Honda, Yamaha and Suzuki motorcycle products. The object of the research was carried out in the Gresik regency. The results of this study were a decision support system for motorcycle product selection using the Simple Additive Weighting (SAW) method that made it easier for users to run the decision support system for selecting the best motor products and support motorbike buyers' decisions in choosing a motor in accordance with the desired criteria.
\end{abstract}

Keywords: Decision support system, simple additive weighting, motor selection

Sitasi: Hermanto. Izzah, N. 2018. Sistem Pendukung Keputusan Pemilihan Motor Dengan Metode Simple Additive Weighting (SAW). Matematika dan Pembelajaran, 6(2), 184-200. 


\section{PENDAHULUAN}

Sepeda motor merupakan alat transportasi yang sangat efektif dan efisien, hal itu dapat dilihat dari setiap tahun dimana jumlah produk motor semakin meningkat. Peningkatan jumlah produk motor tersebut dikarenakan banyaknya konsumen yang mulai menggunakan sepeda motor untuk kegiatan sehari-hari. Produk-produk sepeda motor di Indonesia juga sangat banyak, seperti : Honda, Suzuki, Kawasaki, dan Yamaha. Sehubungan dengan banyaknya produk motor di Indonesia, hal itu membuat banyak konsumen memiliki pilihan tersendiri untuk membeli sepeda motor yang tepat dan sesuai dengan keinginan, kebutuhan dan kemampuannya. Oleh karena itu diperlukan sebuah perhitungan dan penentuan dalam memilih produk motor terbaik dengan menggunakan metode Simple Additive Weighting (SAW).

Metode Simple Additive Weighting sering juga dikenal dengan istilah metode penjumlahan terbobot. Konsep dasar SAW adalah mencari penjumlahan terbobot dari kinerja setiap alternatif pada semua atribut. Metode SAW membutuhkan proses normalisasi matriks keputusan (X) ke suatu skala yang dapat dibandingkan dengan semua rating alternatif yang ada. Metode ini merupakan metode yang paling terkenal dan paling banyak digunakan dalam menghadapi situasi Multiple Attribute Decision Making (MADM). MADM itu sendiri merupakan suatu metode yang digunakan untuk mencari alternatif optimal dari sejumlah alternatif dengan kriteria tertentu. Metode SAW ini mengharuskan pembuat keputusan menentukan bobot bagi setiap atribut. Skor total untuk alternatif diperoleh dengan menjumlahkan seluruh hasil perkalian antara rating (yang dapat dibandingkan lintas atribut) dan bobot tiap atribut. Rating tiap atribut haruslah bebas dimensi dalam arti telah melewati proses normalisasi matriks sebelumnya. (Kusumadewi,2006)

Pada metode SAW terdapat dua atribut, seperti kriteria keuntungan (benefit) dan kriteria biaya (cost). Kedua kriteria tersebut merupakan dasar dalam pemilihan kriteria ketika mengambil keputusan atau menentukan sepeda motor yang akan dipilih. Metode SAW adalah metode yang banyak digunakan untuk menyelesaikan pengambilan keputusan secara praktis, dari pernyataan tersebut dapat dikatakan bahwa metode SAW adalah metode yang efektif dan praktis dalam perhitungan untuk menentukan alternatif produk motor terbaik yang diminati banyak orang dan memiliki banyak keunggulan dalam membantu masyarakat untuk mencari informasi tentang produk-produk motor dari 
berbagai macam jenis di Indonesia, dengan menentukan kriteria yang sesuai mereka harapkan.

Tujuan penelitian ini adalah membuat desain sistem pendukung keputusan pemilihan produk motor dengan metode Simple Additive Weighting (SAW). dengan harapan, penelitian ini dapat membantu bagi pembeli untuk memilih produk motor yang sesuai dengan kriteria-kriteria yang diharapkan, dan berguna bagi pemilik dealer motor untuk melihat kondisi pasar motor.Sistem pendukung keputusan ini hanya membandingkan 3 produk motor Honda,Yamaha dan Suzuki. Obyek penelitian di lakukan di wilayah Kabupaten Gresik.

\section{METODE}

Data Primer adalah data yang didapatkan dari observasi atau penelitian langsung di lapangan. Data primer ini berupa List Produk, List Spesifikasi Produk, List Kriteria, Nilai Bobot Setiap Kriteria dan Nilai bobot sub kriteria. Data sekunder adalah data yang digunakan sebagai pendukung untuk data-data primer, sumber data sekunder diperoleh melalui media perantara atau secara tidak langsung yang berupa buku, jurnal, artikel, bukti yang telah ada, atau arsip baik yang dipublikasikan maupun yang tidak dipublikasikan secara umum.

Sumber data yang diperoleh berdasarkan data yang dibutuhkan dalam penelitian ini adalah masyarakat umum selaku pemakai kendaraan bermotor dan deler motor selaku penjual kendaraan bermotor.

Metode pengumpulan data dalam melakukan penelitian ini dengan cara:

- Metode Wawancara (Interview)

- Observasi / Pengamatan secara langsung

- Dokumentasi

Analisis kebutuhan merupakan sebuah proses untuk mendapatkan informasi tentang pemilihan produk motor terbaik sesuai apa yang di harapkan oleh penggunanya.

Peneliti membuat sebuah sistem pendukung keputusan ini agar dapat mempercepat proses konsumen maupun pemilik deler motor dalam menentukan produk motor yang sesuai dengan harapan para pemakainya,

Dalam analisis kebutuhan data, Kriteria-kriteria yang digunakan dalam menentukan produk motor terbaik antara lain:

1) Harga

2) Kualitas 
3) Desain

4) Purna Jual

5) Konsumsi BBM

6) Popularitas

Perancangan sistem menjelaskan tentang rancangan sistem pendukung keputusan pemilihan motor dengan metode SAW, adapun flowchart sistem terlihat pada gambar 1 sedangkan ERD (Entity Relationship Diagram) terlihat pada gambar 2.

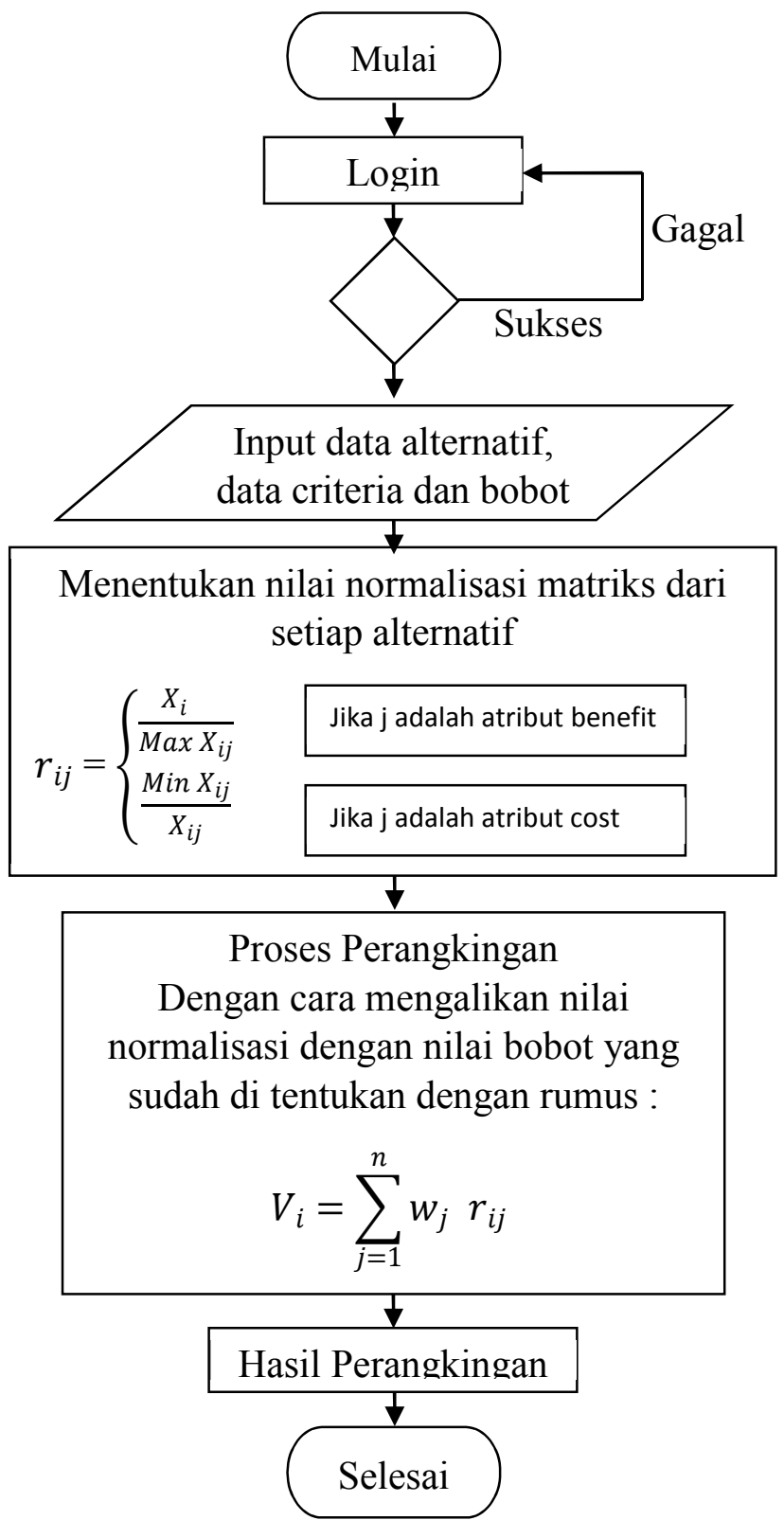

Gambar 1. Flowchart Sistem 


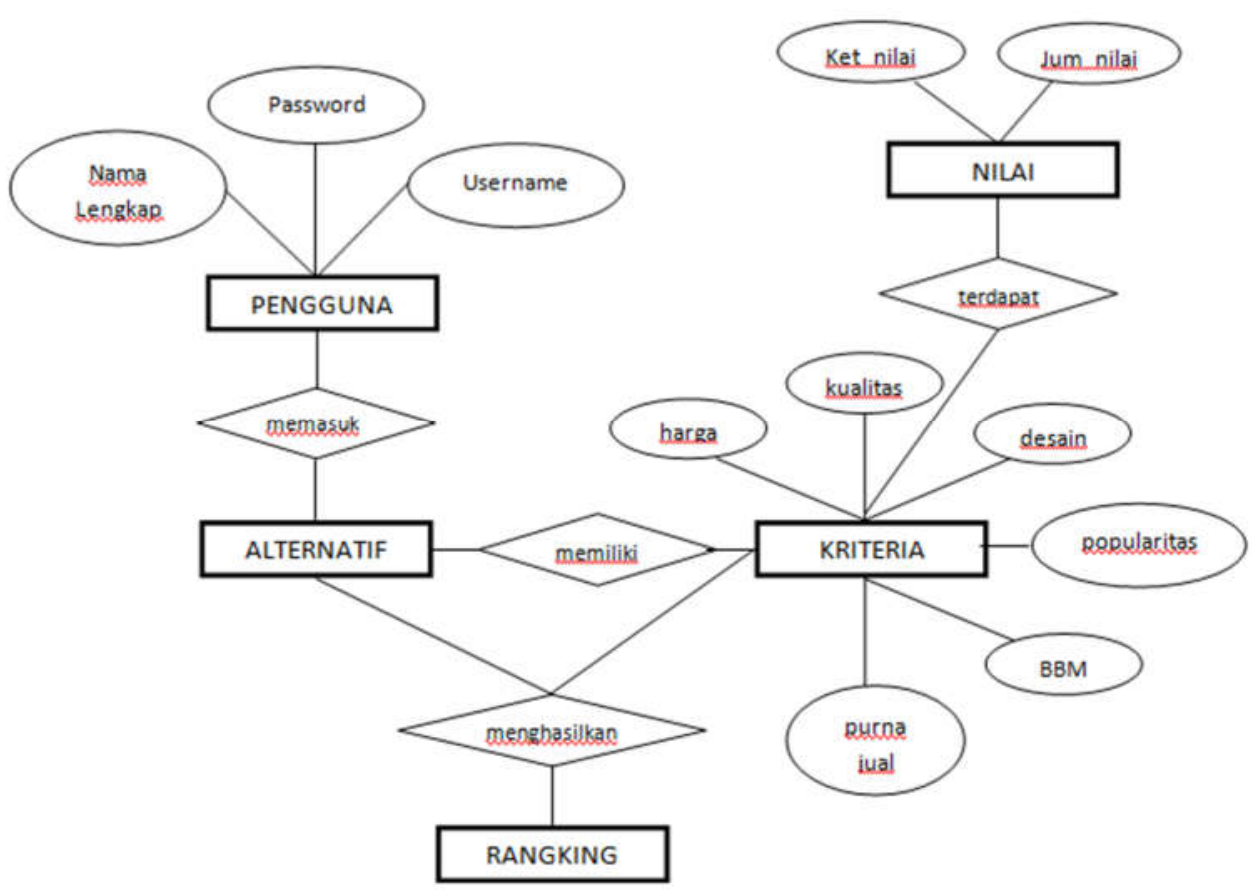

Gambar 2. Entity Relationship Diagram (ERD)

Ada beberapa langkah dalam penyelesaian metode SAW, sebagai berikut :

a. Menentukan kriteria-kriteria yang akan dijadikan acuan dalam pengambilan keputusan, yaitu Ci.

b. Menentukan rating kecocokan setiap alternatif pada setiap kriteria.

c. Membuat matriks keputusan berdasarkan kriteria (Ci), kemudian melakukan normalisasi matriks berdasarkan persamaan yang disesuaikan dengan jenis atribut seperti (atribut keuntungan ataupun atribut biaya) sehingga diperoleh matriks ternormalisasi R.

d. Hasil akhir diperoleh dari proses perankingan yaitu penjumlahan dari perkalian matriks ternormalisasi $\mathrm{R}$ dengan vektor bobot sehingga diperoleh nilai terbesar yang dipilih sebagai alternatif terbaik (Ai) sebagai solusi.

Tahap implementasi sistem merupakan tahap tentang penjelasan proses pembuatan sistem pendukung keputusan pemilihan motor dengan metode SAW yang mengacu pada tahap perancangan.

Tahap pengujian merupakan tahap yang digunakan untuk mengetahui tingkat keandalan sistem. 


\section{HASIL DAN PEMBAHASAN}

Berdasarkan data yang telah dikumpulkan diperoleh data berupa list produk, list spesifikasi produk, list nilai bobot setiap kriteria dan nilai sub kriteria.

\section{Analisis Kebutuhan Perhitungan Metode SAW}

a. Kriteria

Untuk menentukan produk motor terbaik dengan metode Simple Additive Weighting di perlukan beberapa keriteria yang digunakan sebagai acuan dalam pengambilan keputusan, yaitu sebagai berikut:

Tabel 1 Kode dan Ketentuan Kriteria

\begin{tabular}{|l|l|l|l|l|}
\hline NO & $\begin{array}{c}\text { Kode } \\
\text { Kriteria }\end{array}$ & \multicolumn{1}{|c|}{ Ketentuan Kriteria } & \multicolumn{1}{c|}{$\begin{array}{c}\text { Bobot } \\
\text { Kriteria }\end{array}$} & Jenis Atribut \\
\hline 1 & K1 & Harga & 20 & cost \\
\hline 2 & K2 & Kualitas & 20 & benefit \\
\hline 3 & K3 & Desain & 15 & benefit \\
\hline 4 & K4 & Purna Jual & 15 & benefit \\
\hline 5 & K5 & Konsumsi BBM & 15 & cost \\
\hline 6 & K6 & Popularitas & 15 & benefit \\
\hline
\end{tabular}

b.Subkriteria

Tabel 2 Subkriteria Harga

\begin{tabular}{|c|c|c|c|c|c|c|c|}
\hline \multirow[b]{2}{*}{ Harga } & \multirow[b]{2}{*}{ Bobot } & \multicolumn{3}{|c|}{ Batasan } & \multirow[b]{2}{*}{$\begin{array}{c}\text { Matic CC } \\
125\end{array}$} & \multirow[b]{2}{*}{$\begin{array}{l}\text { Matic } \\
\text { CC150 }\end{array}$} & \multirow[b]{2}{*}{$\begin{array}{l}\text { Sport } \\
\text { CC150 }\end{array}$} \\
\hline & & $\begin{array}{l}\text { Bebek } \\
\text { CC110 }\end{array}$ & Bebek CC 125 & Matic CC110 & & & \\
\hline $\begin{array}{l}\text { Sangat } \\
\text { Mahal }\end{array}$ & 4 & $\geq 15.100 .000$ & $\geq 17.100 .000$ & $\geq 16.100 .000$ & $\geq 18.100 .000$ & $\begin{array}{c}\geq 21.000 \\
000\end{array}$ & $\begin{array}{c}\geq 27.000 .0 \\
00\end{array}$ \\
\hline Mahal & 3 & $\begin{array}{c}13.600 .000 \\
-15.000 .000\end{array}$ & $\begin{array}{c}15.600 .000- \\
17.000 .000\end{array}$ & $\begin{array}{l}14.600 .000- \\
16.000 .000\end{array}$ & $\begin{array}{c}16.600 .000- \\
18.000 .000\end{array}$ & $\begin{array}{l}19.600 .0 \\
00- \\
21.000 .0 \\
00\end{array}$ & $\begin{array}{l}25.100 .00 \\
0- \\
27.000 .00 \\
0\end{array}$ \\
\hline $\begin{array}{l}\text { Cukup } \\
\text { Murah }\end{array}$ & 2 & $\begin{array}{c}12.100 .000 \\
-13.500 .000\end{array}$ & $\begin{array}{c}14.100 .000- \\
15.500 .000\end{array}$ & $\begin{array}{c}13.100 .000- \\
14.500 .000\end{array}$ & $\begin{array}{l}15.100 .000- \\
16.500 .000\end{array}$ & $\begin{array}{l}18.100 .0 \\
00- \\
19.500 .0 \\
00\end{array}$ & $\begin{array}{l}23.100 .00 \\
0- \\
25.000 .00 \\
0\end{array}$ \\
\hline Murah & 1 & $\leq 12.000 .000$ & $\leq 14.000 .000$ & $\leq 13.000 .000$ & $\leq 15.000 .000$ & $\begin{array}{l}\leq 18.000 \\
000\end{array}$ & $\begin{array}{l}\leq 23.000 .0 \\
00\end{array}$ \\
\hline
\end{tabular}


Hermanto. Izzah, N.2018. Sistem Pendukung Keputusan Pemilihan Motor... Matematika dan Pembelajaran, 6(2), 190 of 200

Tabel 3 Subkriteria Kualitas

\begin{tabular}{|l|c|}
\hline \multicolumn{1}{|c|}{ Kualitas } & Bobot \\
\hline Sangat Baik & 4 \\
\hline Baik & 3 \\
\hline Cukup & 2 \\
\hline Kurang Baik & 1 \\
\hline
\end{tabular}

Tabel 4 Subkriteria Desain

\begin{tabular}{|c|c|}
\hline Desain & Bobot \\
\hline Sangat Baik & 4 \\
\hline Baik & 3 \\
\hline Cukup Baik & 2 \\
\hline Kurang Baik & 1 \\
\hline
\end{tabular}

Tabel 5 Subkriteria Purna Jual

\begin{tabular}{|l|c|}
\hline \multicolumn{1}{|c|}{ Purna Jual } & Bobot \\
\hline Sangat Mahal & 4 \\
\hline Mahal & 3 \\
\hline Cukup Murah & 2 \\
\hline Murah & 1 \\
\hline
\end{tabular}

Tabel 6 Subkriteria Konsumsi BBM

\begin{tabular}{|l|c|}
\hline \multicolumn{1}{|c|}{ Konsumsi BBM } & Bobot \\
\hline Sangat Tinggi & 4 \\
\hline Tinggi & 3 \\
\hline Cukup & 2 \\
\hline Rendah & 1 \\
\hline
\end{tabular}

Tabel 7 Subkriteria Popularitas

\begin{tabular}{|l|c|}
\hline \multicolumn{1}{|c|}{ Popularitas } & Bobot \\
\hline Sangat Tinggi & 4 \\
\hline Tinggi & 3 \\
\hline Cukup & 2 \\
\hline Rendah & 1 \\
\hline
\end{tabular}

c. Nilai Preferensi

Untuk menentukan produk motor terbaik, terdapat empat nilai kelayakan yang terdiri dari 1-4 yang digunakan untuk pemberian bobot pada masing-masing kriteria. 
Hermanto. Izzah, N.2018. Sistem Pendukung Keputusan Pemilihan Motor... Matematika dan Pembelajaran, 6(2), 191 of 200

Tabel 8 Nilai Preferensi

\begin{tabular}{|c|c|c|}
\hline NO & Keterangan Nilai & Jumlah Nilai \\
\hline 1 & Sangat Tinggi & 4 \\
\hline 2 & Tinggi & 3 \\
\hline 3 & Cukup & 2 \\
\hline 4 & Rendah & 1 \\
\hline
\end{tabular}

d.Alternatif

Ada 3 data sebagai alternatif yang di ambil dalam penelitian ini yaitu :

Tabel 9 Kode dan Ketentuan Alternatif

\begin{tabular}{|c|c|c|}
\hline NO & Alternatif & Nama Alternatif \\
\hline 1 & A1 & HONDA \\
\hline 2 & A2 & YAMAHA \\
\hline 3 & A3 & SUZUKI \\
\hline
\end{tabular}

\section{Implementasi Sistem}

a. Halaman Login

Untuk halaman login terdapat dua button pilihan yaitu pengguna dan admin seperti pada gambar 3

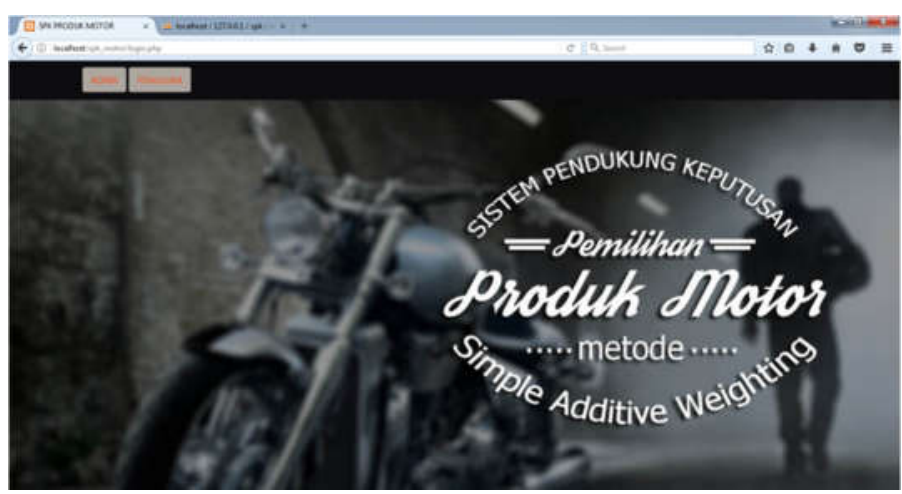

Gambar 3. Halaman Login

b.Halaman Alternatif

Pada halaman alternatif terdapat sebuah tampilan berupa tabel seperti pada gambar 4, yang berisi nama alternati dan aksi untuk edit maupun ubah sebuah alternatif. 
Hermanto. Izzah, N.2018. Sistem Pendukung Keputusan Pemilihan Motor... Matematika dan Pembelajaran, 6(2), 192 of 200
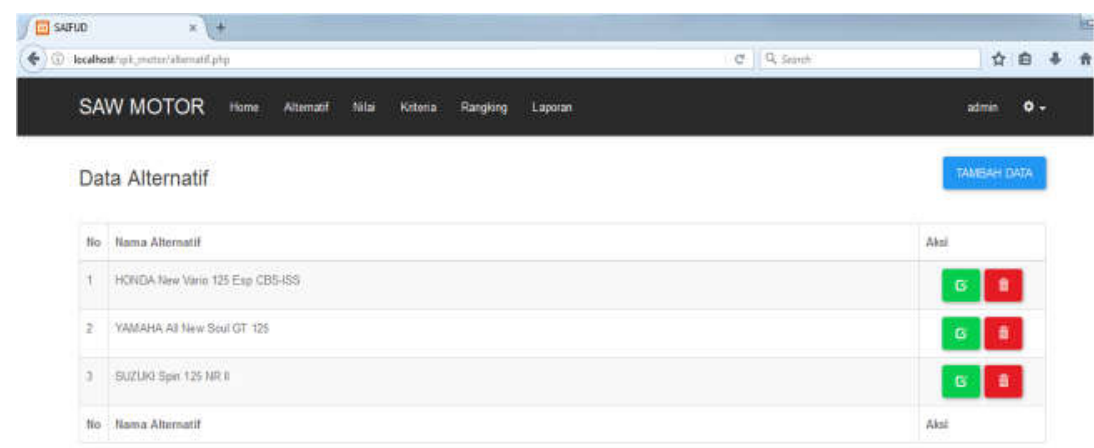

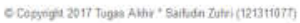

Gambar 4. Halaman Alternatif

\section{c. Halaman Nilai}

Pada halaman nilai ini terdapat tabel keterangan nilai, jumlah nilai dan aksi untuk menghapus atau mengubah data nilai preferensi.

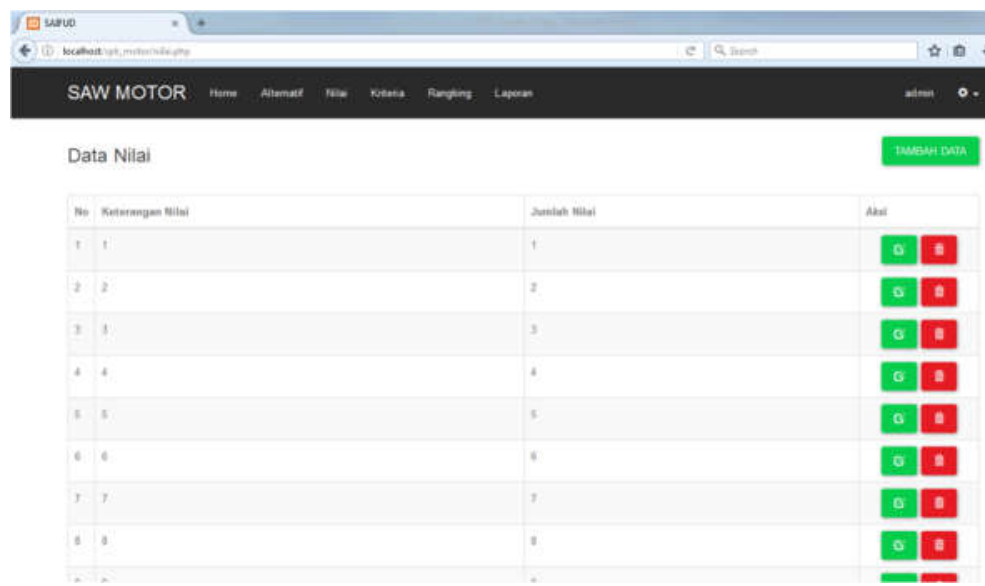

Gambar 5. Halaman Nilai

\section{d.Halaman Kriteria}

Pada halaman kriteria ini terdapat tabel kriteria, tabel tipe kriteria, tabel bobot kriteria dan aksi untuk menghapus atau mengubah data kriteria,. 
Hermanto. Izzah, N.2018. Sistem Pendukung Keputusan Pemilihan Motor... Matematika dan Pembelajaran, 6(2), 193 of 200

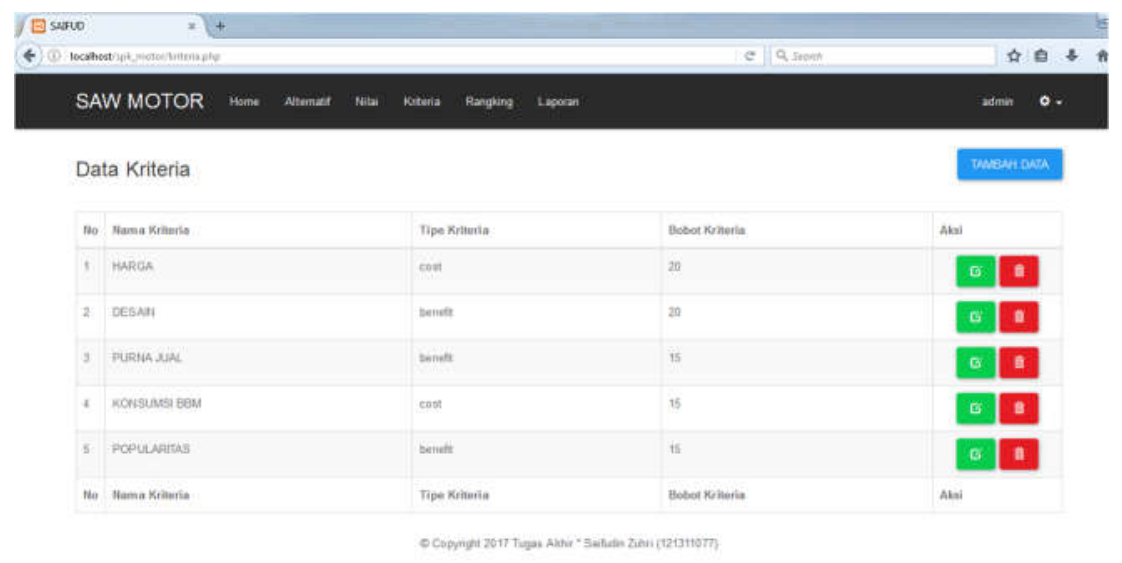

Gambar 6. Halaman Kriteria

\section{e.Halaman Rangking}

Pada halaman rangking terdapat menu lihat data, kemudian perangkingan dan tambah data. Untuk menu lihat data dapat menampilkan data-data yang akan di rangking yaitu alternatif beserta nilai yang didapatkan dari setiap kriteria dan untuk menu perangkingan seperti pada gambar 8 akan menampilkan hasil normalisasi dan hasil perangkingan.

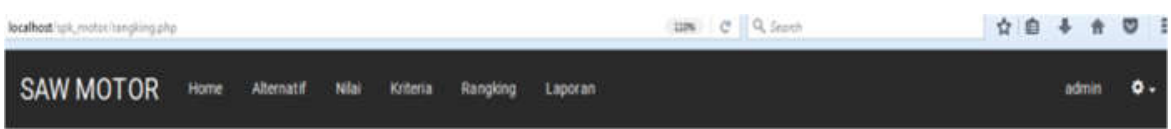

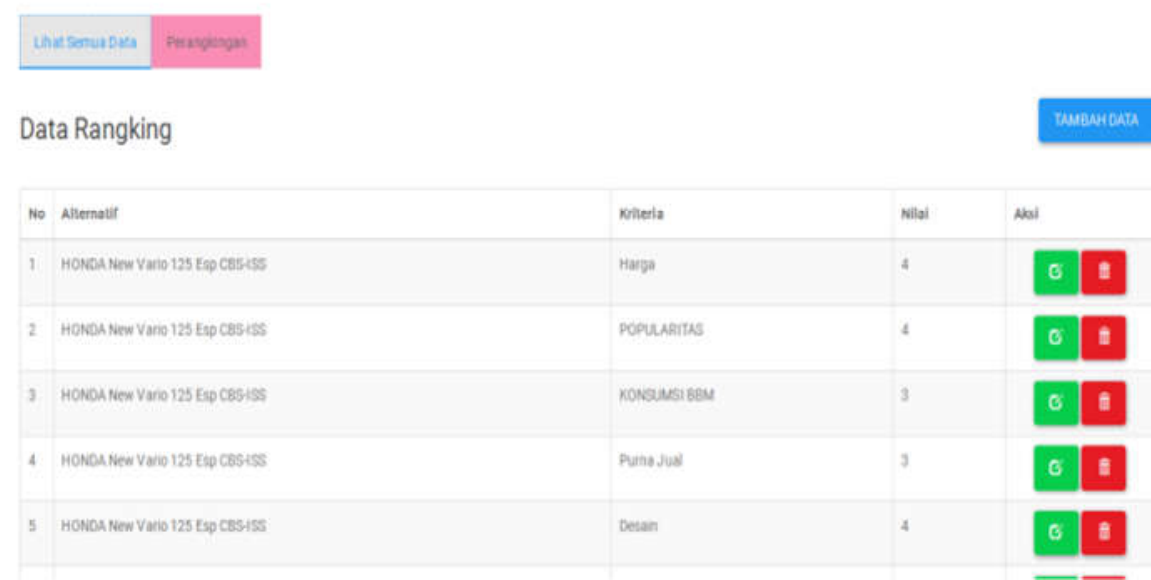

Gambar 7. Halaman Rangking untuk Lihat Data 
Hermanto. Izzah, N.2018. Sistem Pendukung Keputusan Pemilihan Motor... Matematika dan Pembelajaran, 6(2), 194 of 200
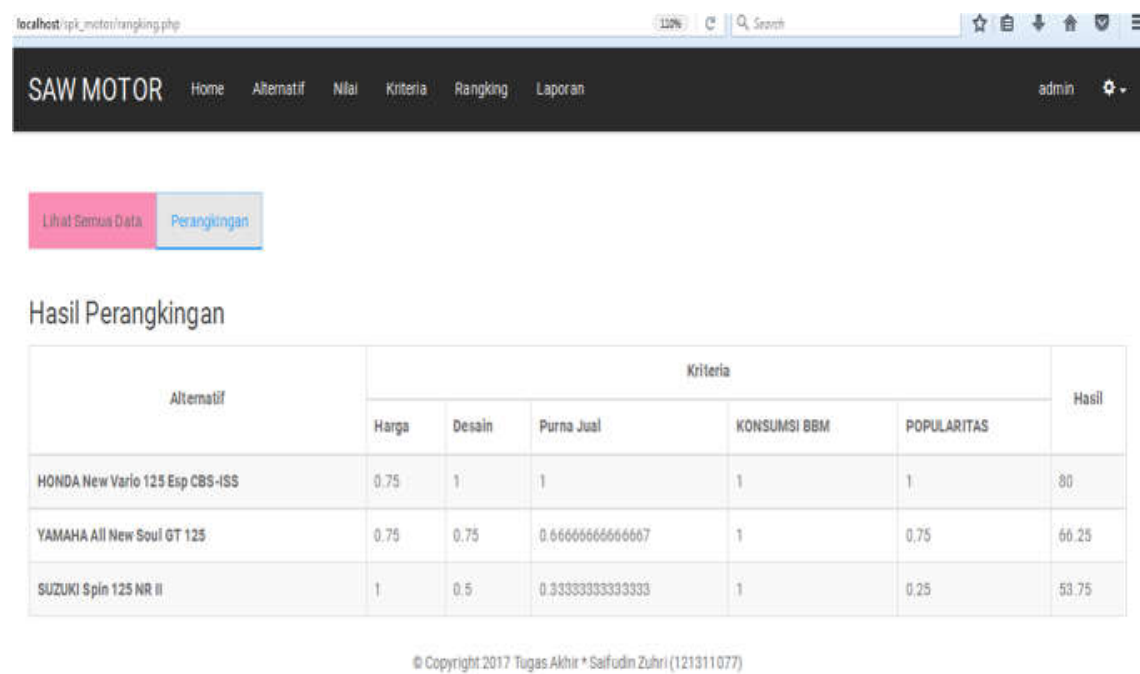

Gambar 8. Halaman Rangking untuk Perangkingan

\section{f.Halaman Laporan}

Pada halaman laporan ini sistem menampilkan seluruh hasil perangkingan menggunkan metode simple additive weighting mulai dari data nilai alternatif kemudian proses normalisasi dan hasil akhir yang di peroleh masing-masing alternatif. 


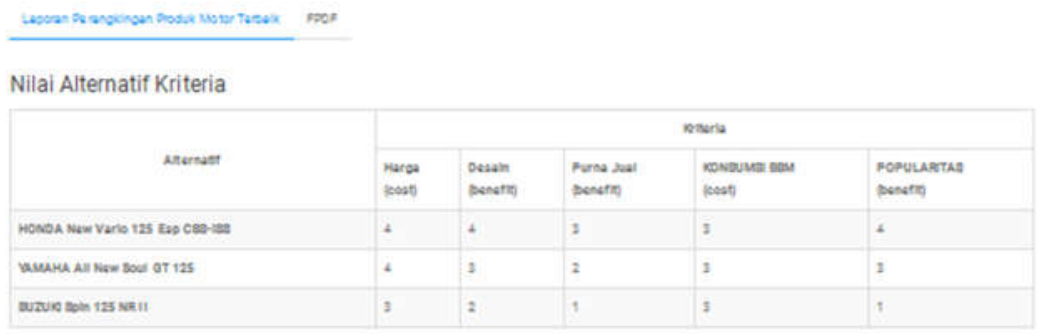

Normalisasi $R$

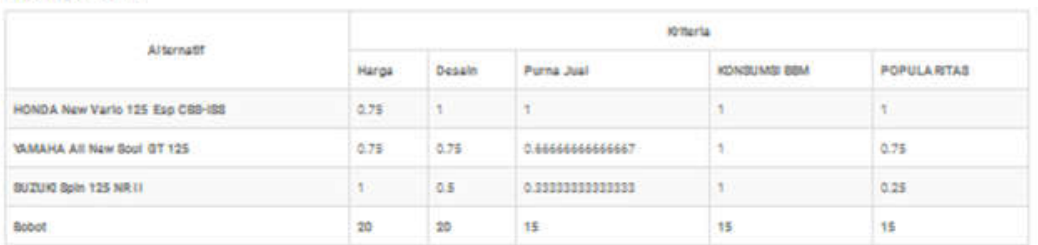

Hasil Akhir

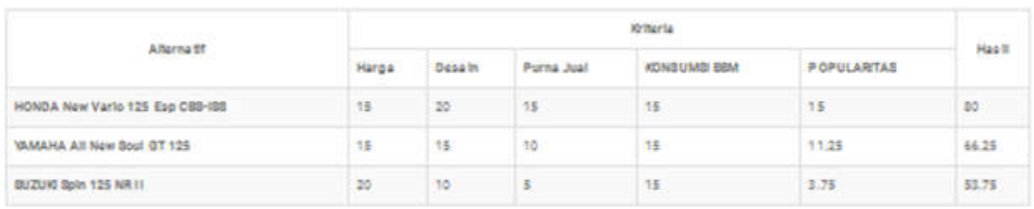

Gambar 9. Halaman Laporan

\section{Pengujian Manual Menggunakan Metode Simple Additive Weighting}

Dalam pengujian ini penulis melakukan pengujian melalui sebuah angket yang akan di isi oleh seorang yang akan membeli sebuah motor, dari sebuah angket itu didapatkan sebuah data sebagai berikut : Motor yang dicari adalah jenis matic dengan 125CC, dengan beberapa kriteria : Harga dengan bobot 20, desain dengan bobot 20, purna jual dengan bobot 15, konsumsi BBM dengan bobot 15, dan popularitas dengan bobot 15. Dan untuk nilai alternatif tiap-tiap kriteria didapatkan sebuah data sebagai berikut:

Tabel 10 Data Nilai Alternatif

\begin{tabular}{|l|l|l|l|l|l|l|}
\hline NO & \multicolumn{1}{|c|}{ Alternatif } & \multicolumn{1}{|c|}{ C1 } & \multicolumn{1}{|c|}{ C2 } & \multicolumn{1}{|c|}{ C3 } & \multicolumn{1}{c|}{ C4 } & \multicolumn{1}{c|}{ C5 } \\
\hline 1 & $\begin{array}{l}\text { HONDA (New Vario 125 Esp } \\
\text { CBS-ISS) }\end{array}$ & 4 & 4 & 3 & 3 & 4 \\
\hline 2 & $\begin{array}{l}\text { YAMAHA (All New Soul GT } \\
\text { 125) }\end{array}$ & 4 & 3 & 2 & 3 & 3 \\
\hline 3 & SUZUKI (Spin 125 NR II) & 3 & 2 & 1 & 3 & 1 \\
\hline
\end{tabular}


Setelah mendapat nilai kecocokan alternatif kemudian dapat di tentukan matriks keputusan sebagai berikut:

$X=\left(\begin{array}{lllll}4 & 4 & 3 & 3 & 4 \\ 4 & 3 & 2 & 3 & 3 \\ 3 & 2 & 1 & 3 & 1\end{array}\right)$

a.Proses Normalisasi

Dalam metode SAW membutuhkan proses normalisasi matriks keputusan (X) kesuatu skala yang dapat diperbandingkan dengan semua rating alternatif yang ada. Dalam perhitungan normalisasi matrik terdapat dua atribut, yaitu atribut keuntungan (benefit) dan atribut biaya (cost), berikut adalah perhitungan matriks normalisasi dari setiap nilai kriteria yang di peroleh oleh setiap alternatif. Untuk harga termasuk ke dalam atribut biaya (cost), karena semakin kecil nilai maka semakin baik.

$\mathrm{r}_{11}=\frac{\min (4,4,3)}{4}=\frac{3}{4}=0.75$

$$
, \mathrm{r}_{21}=\frac{\min (4,4,3)}{4}=\frac{3}{4}=0.75 \quad, \mathrm{r}_{31}=\frac{\min (4,4,3)}{3}=\frac{3}{3}=1
$$

Untuk desain termasuk ke dalam atribut keuntungan (benefit), karena semakin besar nilai maka semakin baik.

$$
\mathrm{r}_{12}=\frac{4}{\max (4,3,2)}=\frac{4}{4}=1 \quad, \mathrm{r}_{22}=\frac{3}{\max (4,3,2)}=\frac{3}{4}=0.75 \quad, \mathrm{r}_{32}=\frac{2}{\max (4,3,2)}=\frac{2}{4}=0.5
$$

Untuk purna jual termasuk ke dalam atribut keuntungan (benefit), karena semakin besar nilai maka semakin baik.

$$
\begin{aligned}
& \mathrm{r}_{12}=\frac{3}{\max (3,2,1)}=\frac{3}{3}=1 \quad, \mathrm{r}_{22}=\frac{2}{\max (3,2,1)}=\frac{2}{3}=0.66666666666667 \\
& \mathrm{r}_{32}=\frac{1}{\max (3,2,1)}=\frac{1}{3}=0.33333333333333
\end{aligned}
$$

Untuk konsumsi BBM termasuk ke dalam atribut biaya (cost), karena semakin kecil nilai maka semakin baik.

$$
\mathrm{r}_{11}=\frac{\min (3,3,3)}{3}=\frac{3}{3}=1 \quad, \mathrm{r}_{21}=\frac{\min (3,3,3)}{3}=\frac{3}{3}=1 \quad, \mathrm{r}_{31}=\frac{\min (3,3,3)}{3}=\frac{3}{3}=1
$$

Untuk popularitas termasuk ke dalam atribut keuntungan (benefit), karena semakin besar nilai maka semakin baik.

$$
\mathrm{r}_{12}=\frac{4}{\max (4,3,1)}=\frac{4}{4}=1, \quad \mathrm{r}_{22}=\frac{3}{\max (4,3,1)}=\frac{3}{4}=0.75 \quad, \mathrm{r}_{32}=\frac{1}{\max (4,3,1)}=\frac{1}{4}=0.25
$$


Sehingga diperoleh matrik ternormalisasi (R) sebagai berikut:

$X=\left(\begin{array}{ccccc}0.75 & 1 & 1 & 1 & 1 \\ 0.75 & 0.75 & 0.66666666666667 & 1 & 0.75 \\ 1 & 0.5 & 0.33333333333333 & 1 & 0.25\end{array}\right)$

b.Menghitung perangkingan

Setelah dilakukan proses normalisasi matrik langkah selanjutnya adalah proses perangkingan, dalam proses perangkingan diperlukan ranting kepentingan pada setiap kriteria sesuai dengan nilai yang di berikan oleh pengambil keputusan.

$\mathrm{W}=[20 ; 20 ; 15 ; 15 ; 15]$

$\mathrm{W}=[\mathrm{C} 1 ; \mathrm{C} 2 ; \mathrm{C} 3 ; \mathrm{C} 4 ; \mathrm{C} 5]$

Proses perangkingan diperoleh dengan rumus sebagai berikut:

$$
\begin{aligned}
& V_{i}=\sum_{j=1}^{n} w_{j} r_{i j} \\
& \mathrm{~V} 1=(20)(0.75)+(20)(1)+(15)(1)+(15)(1)+(15)(1) \\
& =15+20+15+15+15 \\
& =80 \\
& \mathrm{~V} 2=(20)(0.75)+(20)(0.75)+(15)(0.66666666666667)+(15)(1)+(15)(0.75) \\
& =15+15+10+15+11.25 \\
& =66.25 \\
& \mathrm{~V} 3=(20)(1)+(20)(0.5)+(15)(0.33333333333333)+(15)(1)+(15)(0.25) \\
& =20+10+5+15+3.75 \\
& =53.75
\end{aligned}
$$

c.Hasil Akhir

Setelah melakukan proses perangkingan, maka dapat dihasilkan nilai rangking sebagai berikut:

Tabel 11 Nilai Rangking

\begin{tabular}{|c|c|c|}
\hline NO & ALTERNATIF & NILAI RANGKING \\
\hline 1 & HONDA New Vario 125 Esp CBS-ISS & 80 \\
\hline 2 & YAMAHA All New Soul GT 125 & 66.25 \\
\hline 3 & SUZUKI Spin 125 NR II & 53.75 \\
\hline
\end{tabular}


Dari hasil perangkingan tersebut maka di peroleh hasil V1 adalah yang tertiggi dan V3 adalah yang terendah, dimana V1 adalah produk HONDA New Vario 125 Esp CBS-ISS dan V3 adalah produk SUZUKI Spin 125 NR II.

\section{Pengujian Sistem Menggunakan Metode Simple Additive Weighting}
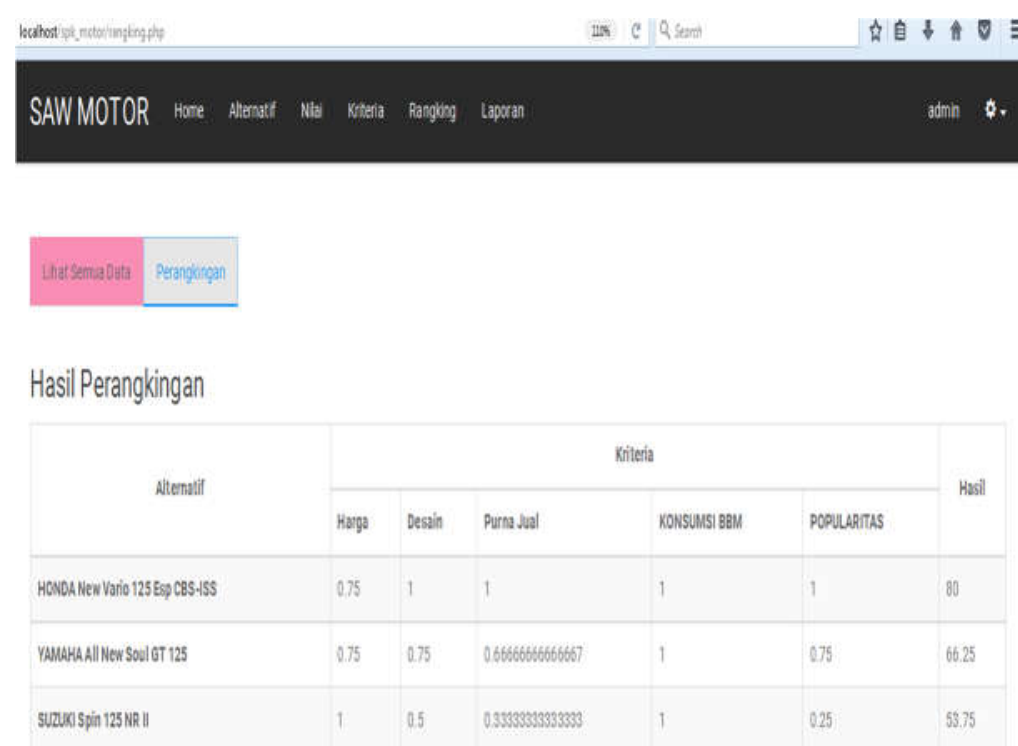

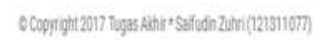

Gambar 10. Halaman Perangkingan

Setelah melakukukan perhitungan manual selanjutnya akan diuji dalam sistem yang sudah dibuat dan hasil dari pengujian sistem yaitu nilai tertinggi terdapat pada alternatif motor Honda New Vario 125 Esp CBS-ISS dengan nilai 80.

Berdasarkan kedua pengujian, dimana pengujian manual menunjukkan hasil 80, pengujian sistem juga mendapatkan hasil yang sama yaitu 80 . keduanya menunjukkan bahwa alternatif motor Honda New Vario 125 Esp CBS-ISS mendapatkan nilai akhir tertinggi. Hal tersebut membuktikan bahwa sistem yang dibangun telah berhasil dalam melakukan proses perhitungan menggunakan metode simple additive weighting karena hasil kedua pengujian menunjukkan hasil yang sama. 


\section{KESIMPULAN DAN SARAN}

Berdasarkan kegiatan yang telah dilakukan selama perancangan sampai implementasi sistem pendukung keputusan pemilihan produk motor dengan metode simple additive weighting ini, maka diambil beberapa simpulan sebagai berikut:

a. Rancangan desain sistem pendukung keputusan pemilihan produk motor dengan metode Simple Additive Weighting (SAW) menghasilkan temuan sebuah desain yang mampu mempermudah pengguna dalam menjalankan sistem pendukung keputusan pemilihan produk motor terbaik.

b. Rancangan aplikasi sistem pendukung keputusan pemilihan produk motor dengan metode simple additive weighting menghasilkan temuan bahwa aplikasi tersebut dapat digunakan untuk mendukung keputusan pembeli motor dalam memilih motor sesuai dengan kriteria yang di inginkan.

c. Penerapan Metode simple additive weighting pada sistem pendukung keputusan pemilihan produk motor menunjukkan bahwa aplikasi tersebut dinyatakan dengan hasil nilai terbesar pada alternatif produk motor Honda New Vario 125 Esp CBS-ISS dengan nilai 80, dengan demikian produk motor Honda New Vario 125 Esp CBS-ISS adalah rekomendasi produk dengan nilai tertinggi.

\section{DAFTAR RUJUKAN}

Bonczek, R. H., Holsapple, C. W., dan A. B. Whinston. (1980). 'The Evolving Roles of Models in Decision Support Systems, Decision Science.

Cossalter, Vittore (2006). Motorcycle Dynamics. Lulus. ISBN 978-1-4303-0861-4.

Eniyati, Sri. (2011) ,"Perancangan Sistem Pendukung Keputusan untuk Penerimaan Beasiswa Dengan Metode SAW (Simple Additive Weighting)”, Jurnal Sistem Informasi Universitas Stikubank,Vol.16,No.2, hal.171-176.

Fishburn.(1967). "Additive Utilities with Incomplete Product Set Aplicationto Prioties and Assignments".

Kusrini. (2007). “Konsep dan Aplikasi Sistem Pendukung Keputusan”, Andi Offset, Yogyakarta. 
Kusumadewi, Sri.(2006). "Fuzzy Multi-Attribute Decision Making (FMADM)”, Graha, Yogyakarta.

Kusumadewi, Sri, Sri Hartati, Agus Harjoko, and Retantyo Wardoyo. (2006). “ Fuzzy Multi-Attribute Decision Making (FUZZY MADM)”. GRAHA ILMU.

MacCrimmon,K.R. (1968). "Decision Making Among Multiple Atribut Alternatives: a Survey and Consolidated Approach".

Moore, J. H., dan Chang, M. G. (1980) "Design of Decision Support Systems, Data Base, Vol. 12, No. 1 dan 2.

Sprague, dan Carlson (1993). "Building Effective Decision Support Systems". Prentice Hall Professional Technical Reference, Indianapolis, IN, US (United States)

Turban, Efraim, and Jay E. Aronson. (2005). "Decision Support System and Intelligent System", 6th ed. Andi,Yogyakarta

Yoga, Fitro dan Achmad (2016). "Rancang Bangun Sistem Penentuan Penerima Beasiswa Dengan Metode Simple Additive Weighting (SAW)", Jurnal Speed, Vol 8 No 2 hal 23-32. 